\title{
A UWB Bidirectional Rectangular Ring Antenna Fed by CDM with a Rod and Ridges for Constant Beam Direction
}

\author{
S. Vongsack, ${ }^{1}$ S. Lamultree, ${ }^{2}$ P. Osklang, ${ }^{3}$ C. Phongcharoenpanich, ${ }^{3}$ \\ S. Kosulvit, ${ }^{3}$ K. Hamamoto, ${ }^{4}$ and T. Wakabayashi ${ }^{5}$ \\ ${ }^{1}$ International College, King Mongkut's Institute of Technology Ladkrabang, Bangkok 10520, Thailand \\ ${ }^{2}$ Faculty of Engineering and Technology, Asian University, Chonburi 20260, Thailand \\ ${ }^{3}$ Faculty of Engineering, King Mongkut's Institute of Technology Ladkrabang, Bangkok 10520, Thailand \\ ${ }^{4}$ School of Information and Telecommunication Engineering, Tokai University, Kanagawa 259-1292, Japan \\ ${ }^{5}$ Malaysia-Japan International Institute of Technology (MJIIT), Universiti Technologi Malaysia, Kuala Lumpur 54100, Malaysia
}

Correspondence should be addressed to S. Lamultree, suthasineel@asianust.ac.th

Received 3 January 2012; Accepted 1 March 2012

Academic Editor: Beatriz Ortega

Copyright () 2012 S. Vongsack et al. This is an open access article distributed under the Creative Commons Attribution License, which permits unrestricted use, distribution, and reproduction in any medium, provided the original work is properly cited.

\begin{abstract}
This paper presents an ultra-wideband (UWB) rectangular ring antenna excited by a circular disc monopole (CDM) with a conducting rod and two double ridges to radiate bidirectional pattern with constant beam direction along the entire UWB frequency range of 3.1-10.6 GHz. The conducting rod and double ridges at the upper wall of the ring are added to solve the tilted beam problem at the higher edge frequency whereas the double ridges at the lower wall are used to enhance the impedance bandwidth. The dimensions of the rectangular ring and the CDM are initially considered to achieve the bidirectional pattern with the suitable resonant frequencies and bandwidth. Then, the parameters of copper rod and two double ridges are determined by parametric study using CST Microwave Studio simulation software. The prototype antenna was fabricated, and the measured results show good agreement with the simulated ones. The obtained bandwidth of $\left|\mathrm{S}_{11}\right|<-10 \mathrm{~dB}$ can cover the UWB frequency range as well as the bidirectional beam radiation with constant beam direction $\left(\theta=0^{\circ}, 180^{\circ}\right.$ and $\left.\phi=90^{\circ}\right)$. The minimum and maximum measured gains are $3.1 \mathrm{dBi}$ to $5.3 \mathrm{dBi}$, respectively. The proposed antenna possesses compact size with good radiation performance that can be a promising candidate for UWB applications.
\end{abstract}

\section{Introduction}

Nowadays, the wireless communication systems become the significant part of daily-life essence. The ultra-wideband (UWB) is a key technology for future short-range, highspeed, and indoor-data wireless communication. UWB technology is extensively and continuously spread since the regulation of Federal Communication Commission (FCC) defined the frequency spectrum from $3.1 \mathrm{GHz}$ to $10.6 \mathrm{GHz}$ for this system [1]. The demand for the multipurpose and multifunction of this system imposes inevitably the use of antenna to cover very wideband frequency range. For the typical cellular system, the service area is decomposed into small cells for the urban area. The cell shape is approximated by a circle where omnidirectional antenna plays a vital role to employ at the base station [2]. However, for some specific application that requires the long-range service area such as point-to-point communication between the buildings, when the mobiles move along the confined paths such as street, highways, tunnels, and corridors, for these environments, a unidirectional or bidirectional antennas are more suitable than the omnidirectional one to serve these demands [36]. The omnidirectional monopole antenna is modified by adding different shapes of reflectors such as planar reflector [7], corner reflectors $[8,9]$, curved reflectors $[10]$, ring reflectors [11], and others to obtain the unidirectional or bidirectional beams. To enhance the bandwidth, the linear monopole is extended to surface monopole [12] or three-dimensional (3D) monopole [13-15]. To realize the bidirectional pattern along the UWB frequency range, this paper presents the circular disc monopole (CDM) excited rectangular ring antenna. However, the beam direction at 


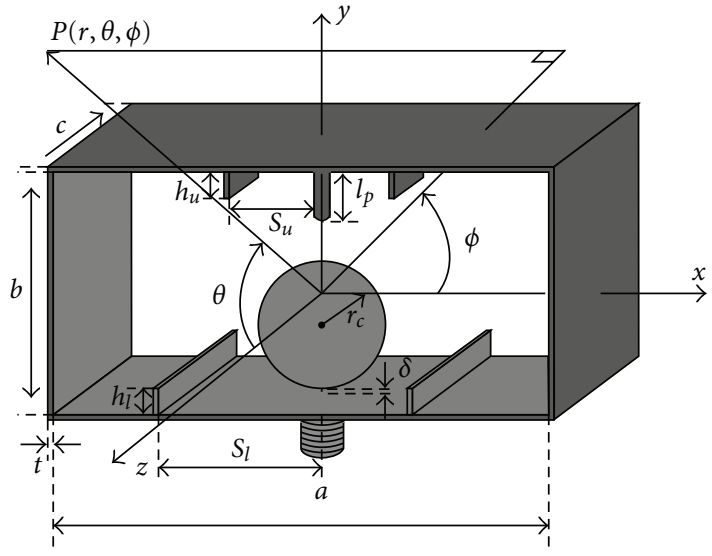

Figure 1: Antenna structure.

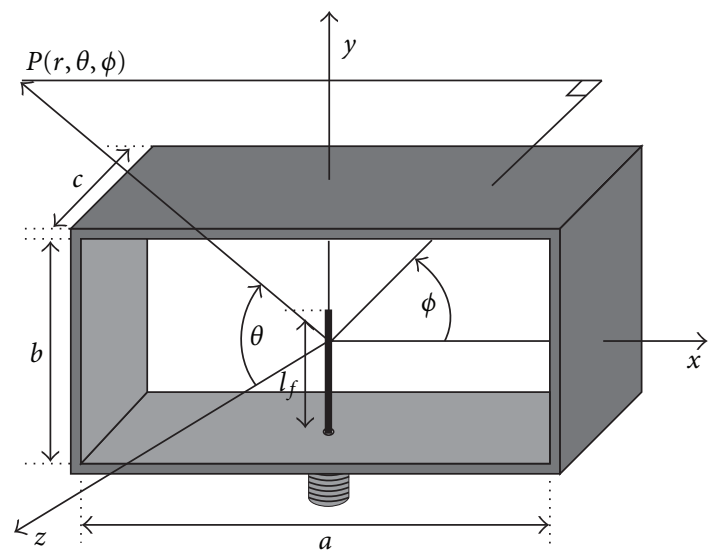

Figure 2: An initial antenna structure.

the higher edge frequency is tilted due to unsymmetrical structure of the antenna along the upper and lower parts of the ring. The conducting rod and two double ridges are added at the upper wall of the ring to induce the current along the upper part of the ring that makes the constant beam direction at the higher edge frequency. This tilted beam problem can be solved at the expense of slightly narrower impedance bandwidth. To enhance the impedance bandwidth to meet the frequency requirement of UWB system along $3.1-10.6 \mathrm{GHz}$, the double ridges at the lower wall of the ring are added. The design of this antenna is easy and straightforward. The ring dimension and radius of CDM are firstly considered to operate at the desired resonant frequency with very wide bandwidth. Subsequently, the appropriate parameters of conducting rod and two double ridges are determined from the parametric study. The antenna characteristics such as $\left|S_{11}\right|$, radiation pattern, and gain along the UWB frequency are reported.

The content of this paper is organized as follows. The proposed antenna structure and its parameters are illustrated in Section 2. Section 3 describes the design principle and parametric study. To verify the simulated results, Section 4 presents the measured results. The conclusions are drawn in Section 5.

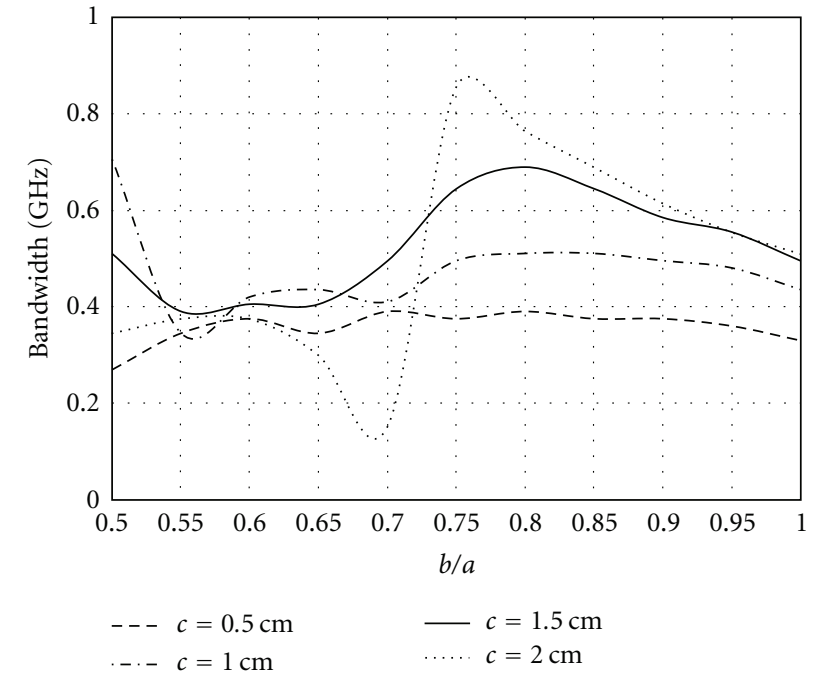

FIGURE 3: Bandwidth of the lower resonant frequency as the function of $b / a\left(a=5 \mathrm{~cm}\right.$ and $\left.l_{f}=2.5 \mathrm{~cm}\right)$.

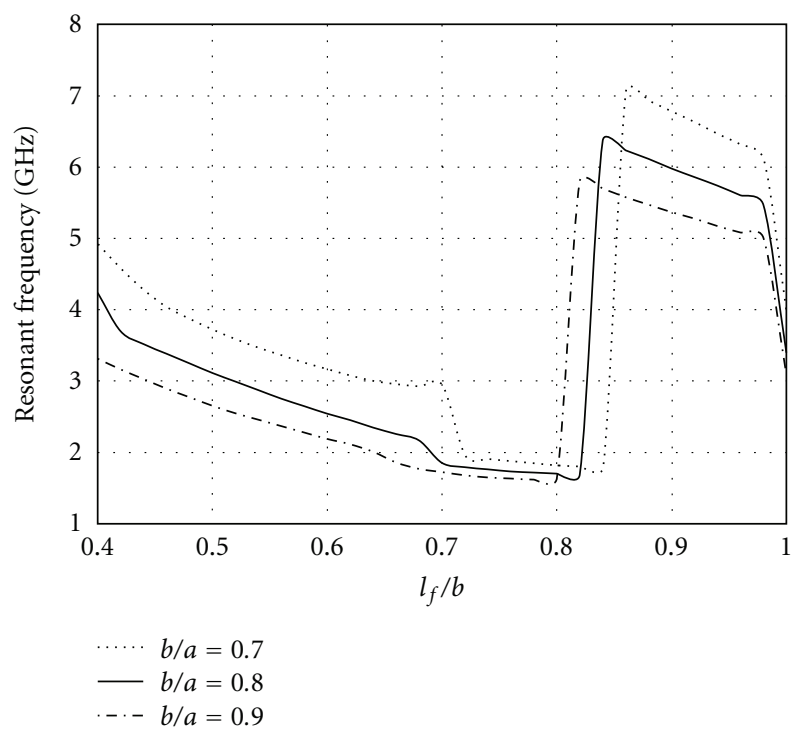

FIGURE 4: The lower resonant frequency for various $l_{f} / b(a=5 \mathrm{~cm}$ and $c=1.5 \mathrm{~cm}$ ).

\section{Antenna Description}

The proposed antenna structure consists of the rectangular ring excited by CDM as shown in Figure 1. The ring is used to confine the CDM radiating omnidirectional pattern to become bidirectional beam. The ring is made of metallic material with the width of $a$, the height of $b$, and the length of $c$. The thickness of the ring is denoted by $t$. This structure is excited by the CDM of the radius $r_{c}$ via $50 \Omega$ SMA connector with delta gap $\delta$. The CDM is located at the center of the lower wall of the ring. The copper rod of the length $l_{p}$ is located at the center of the upper wall of the ring. The double ridge of the height $h_{u}$ is located with $s_{u}$ apart from the ring 


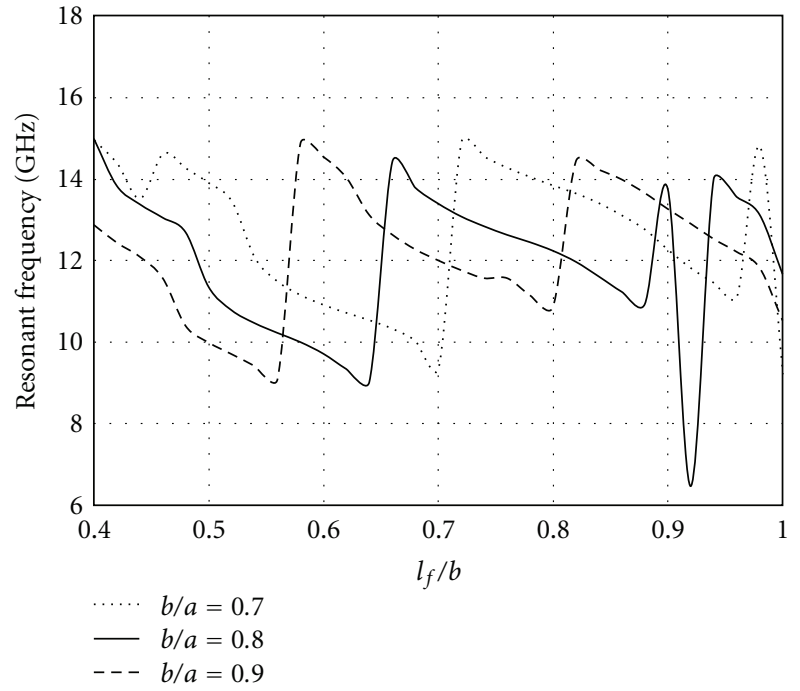

Figure 5: The upper resonant frequency for various $l_{f} / b(a=5 \mathrm{~cm}$ and $c=1.5 \mathrm{~cm}$ ).

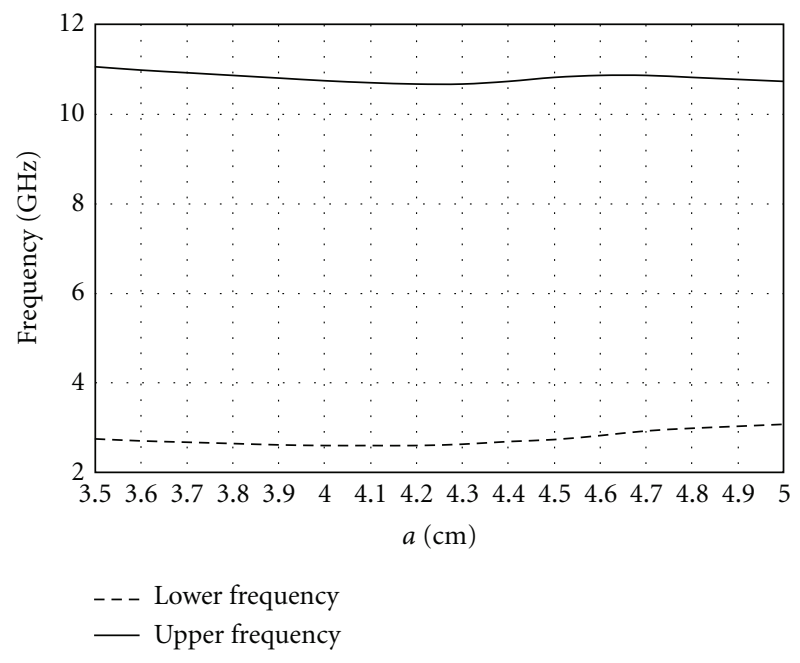

FIGURE 6: Resonant frequency for various $a\left(b / a=0.7, l_{f}=0.62 b\right)$.

center on the upper wall of the ring. At the lower wall of the ring, there are double ridges of the height $h_{l}$ located at the distance $s_{l}$ from the center. It is noted that the length of the ridges is identical to the length of the ring $(c)$.

\section{Design Principle and Parametric Study}

The principle of the antenna design starts with consideration of the conventional linear monopole antenna of the length $l_{f}$. This structure radiates the omnidirectional beam. To obtain the bidirectional pattern, this structure is surrounded by the rectangular ring to focus the main beam into two opposite directions along $+z$ and $-z$ axes as shown in Figure 2. The initial parameter of the ring width $a$ of $5 \mathrm{~cm}(\lambda / 2)$ is chosen with $T E_{10}$ mode operation at $3 \mathrm{GHz}$ that is around the lower edge frequency of UWB. It is noted that the ring in this paper

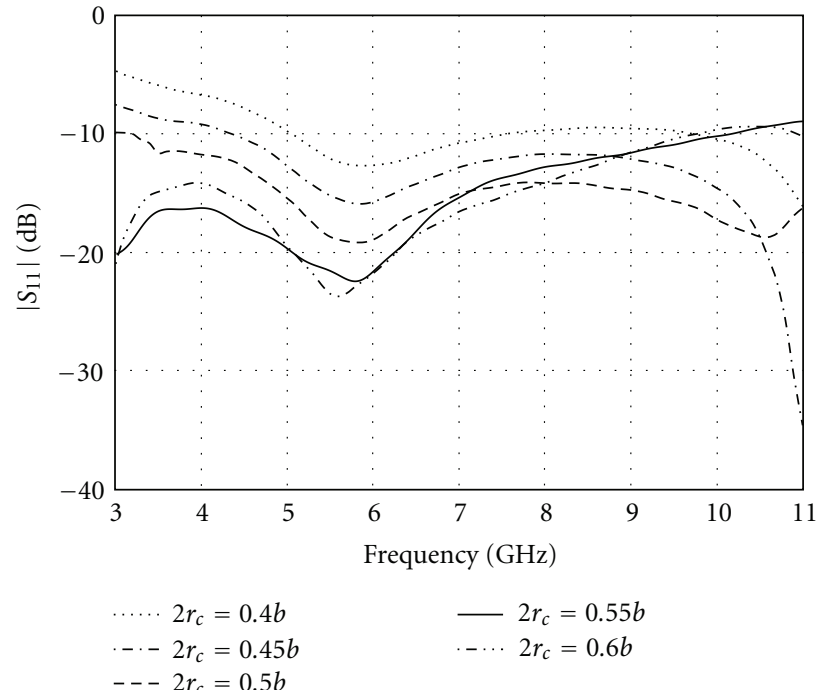

FIgURE 7: $\left|S_{11}\right|$ versus frequency as a function of $2 r_{c}$.

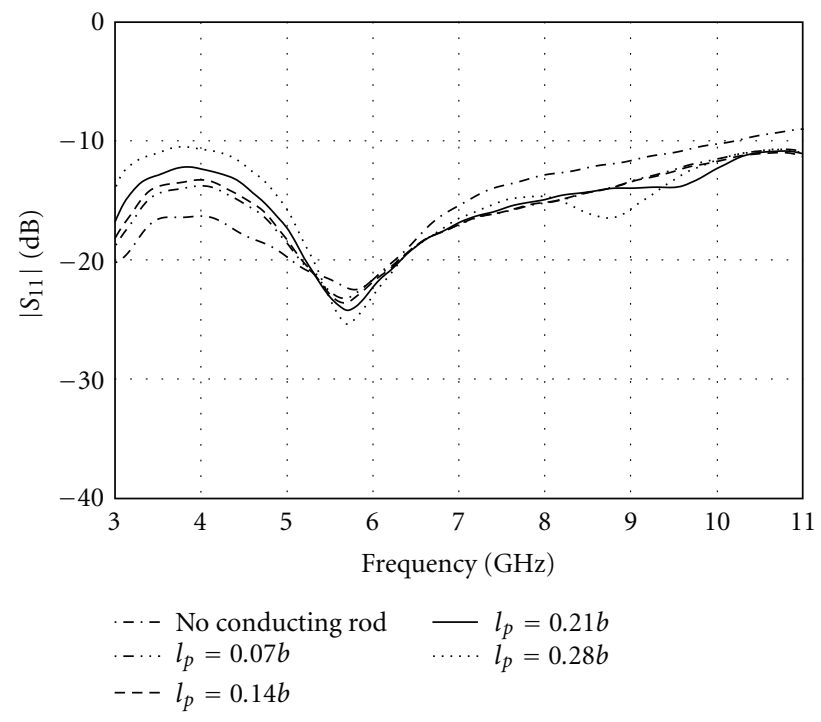

FIGURE 8: $\left|S_{11}\right|$ versus frequency as a function of $l_{p}$.

is made of aluminum with thickness $t$ of $8 \mathrm{~mm}$ for the reason of available fabricated material.

The length $l_{f}$ of linear monopole is $\lambda / 4$ at $3 \mathrm{GHz}\left(l_{f}=\right.$ $2.5 \mathrm{~cm}$ ). Figure 3 shows the bandwidth of the resonant frequency closest to the frequency of $3 \mathrm{GHz}$ as a function of the ratio between the height and the width $(b / a)$ of the ring for different ring lengths $(c)$. The CST Microwave Studio [16] is used as the simulation tool.

From Figure 3, the ring dimensions of $a, b$, and $c$ can be selected from the compact size with the widest bandwidth. Therefore, the ring width $(a)$ of $5 \mathrm{~cm}$, ring height $(b)$ of $3.5 \mathrm{~cm}(b / a=0.7)$, and ring length $(c)$ of $1.5 \mathrm{~cm}$ are chosen. The next step is to find the suitable feeding structure and its dimension to cover the UWB frequency range of 3.110.6 GHz. The linear monopole is the simplest structure 

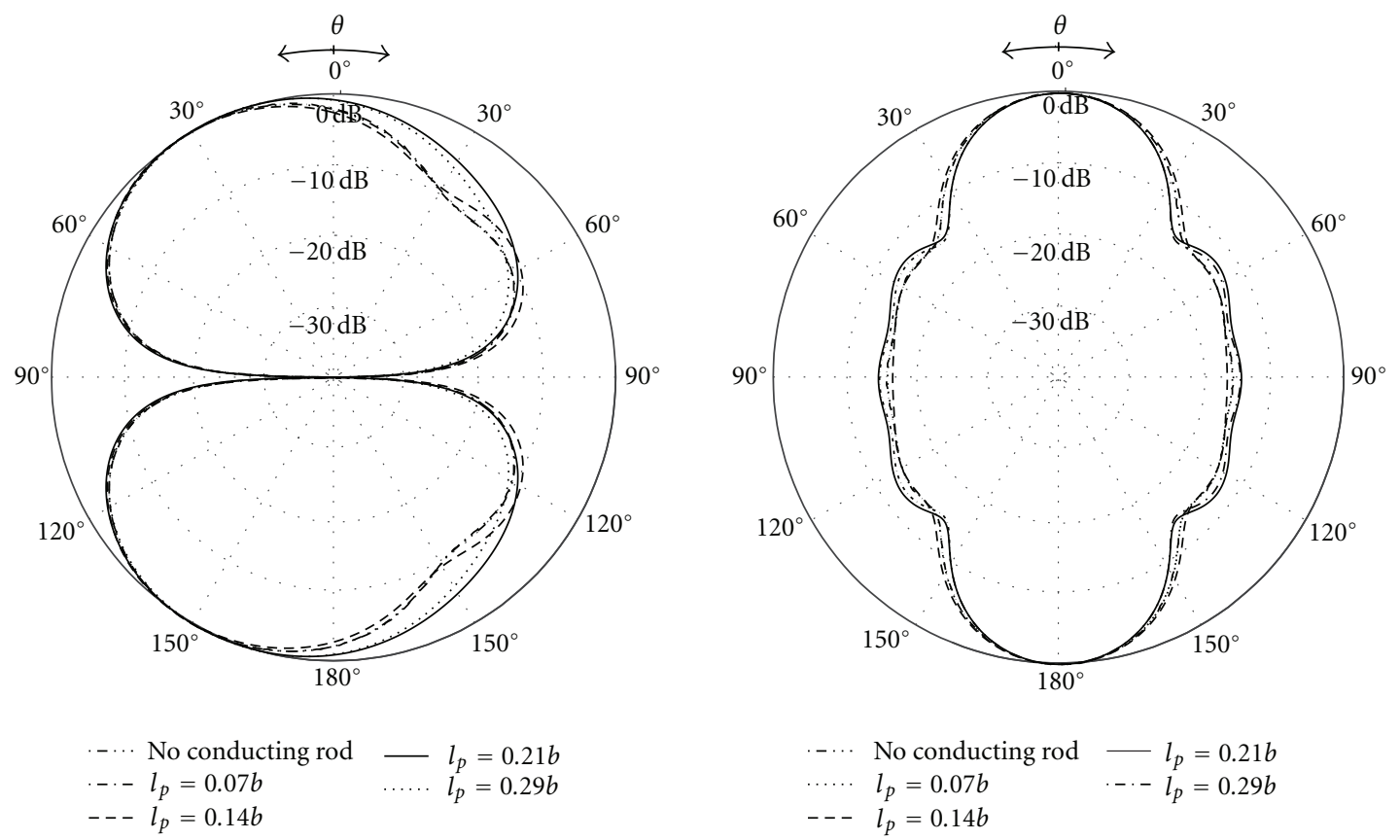

FIgURE 9: The radiation pattern in $y z$ and $x z$ planes as a function of $l_{p}$ at $10.6 \mathrm{GHz}$.

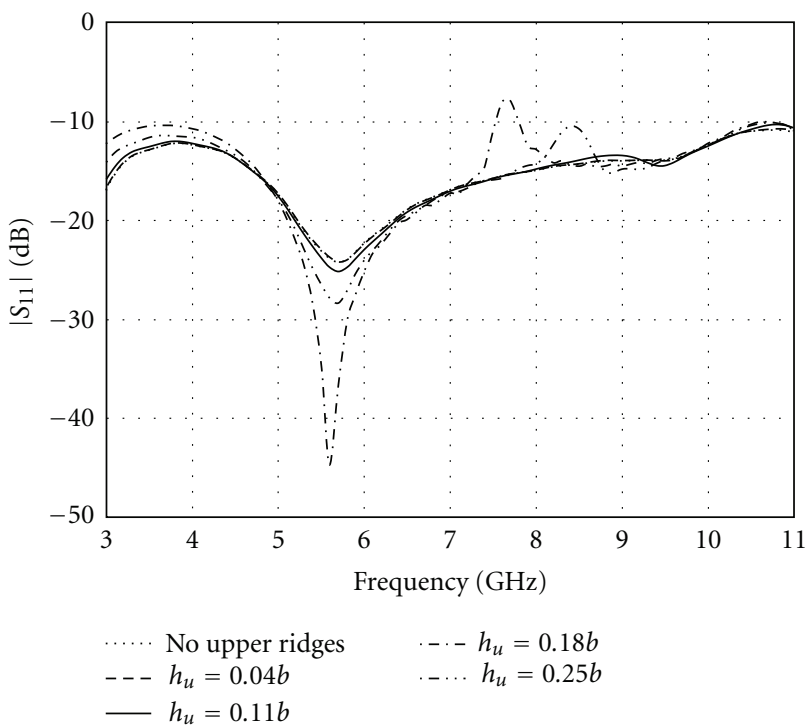

FIgURE 10: $\left|S_{11}\right|$ versus frequency as a function of $h_{u}$.

for consideration. Figures 4 and 5 show the lower and upper resonant frequencies of the rectangular ring with the dimension mentioned above, and it is excited by the linear electric probe of the length $l_{f}$. The dimension of the probe length is expressed in term of $l_{f} / b$ ratio. To achieve the lower and upper resonant frequencies of 3.1 and $10.6 \mathrm{GHz}$, respectively, the length of the probe can be selected from different $b / a$. For example, if $b / a$ is 0.7 , the probe length should be $0.62 b$. In the same fashion, the suitable $l_{f} / b$ for $b / a=0.8$ and $b / a=0.9$ are 0.52 and 1.0 , respectively. For compact size, $l_{f}=0.62 b$ for $b=0.7 a$ is chosen in this paper. Then, the effect of the ring width is studied to determine the possible smallest size. Figure 6 shows the lower and upper resonant frequencies as a function of the ring width. It is apparent that the suitable ring width is $4 \mathrm{~cm}$. Therefore, the dimension of the ring of $a=4 \mathrm{~cm}, b=0.7 a=2.8 \mathrm{~cm}, c=$ $1.5 \mathrm{~cm}$ is used hereafter.

To extend the bandwidth of the antenna, the onedimensional feeding structure of linear monopole will be modified to two-dimensional monopole, that is CDM. The $\mathrm{CDM}$ is introduced to increase the bandwidth to $7.5 \mathrm{GHz}$ (UWB: $3.1-10.6 \mathrm{GHz}$ ). The radius $r_{c}$ of $\mathrm{CDM}$ is varied to determine the appropriate dimension. Figure 7 shows the $\left|S_{11}\right|$ as the function of the frequency for various diameters 

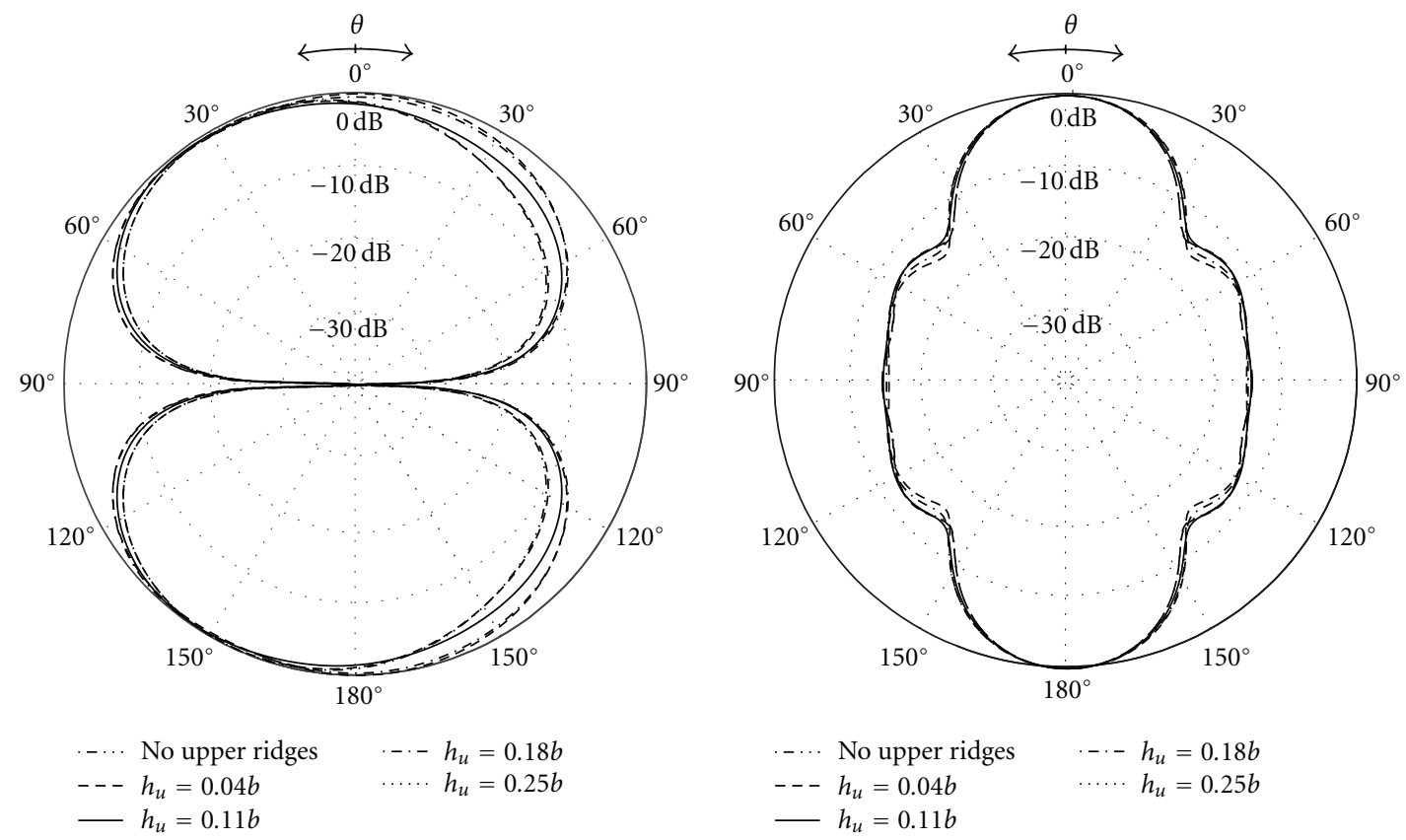

FIGURE 11: The radiation pattern in $y z$ and $x z$ planes as a function of $h_{u}$ at $10.6 \mathrm{GHz}$.

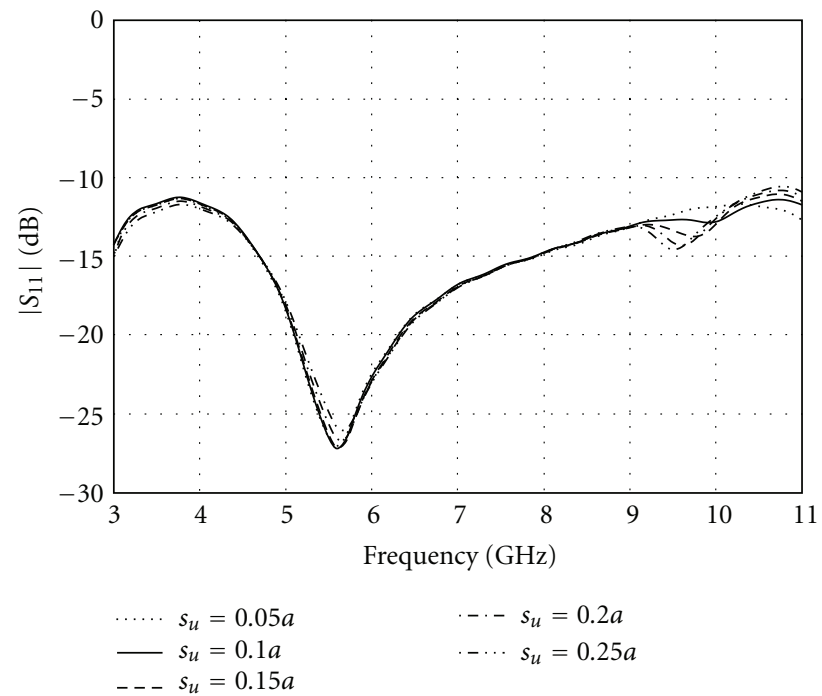

FIgURE 12: $\left|S_{11}\right|$ versus frequency as a function of $s_{u}$.

$\left(2 r_{c}\right)$ of CDM. It is obvious that $2 r_{c}$ of $0.55 b$ or $1.5 \mathrm{~cm}$ is chosen to cover UWB frequency range. At this step, the bidirectional pattern along the frequency range of 3.010.2 $\mathrm{GHz}$ is obtained.

Figures 8 and 9 show the $\left|S_{11}\right|$ and the radiation pattern for different rod lengths compared with case of without conducting rod. The bandwidth can be further enhanced by adding conduction rod. It can be seen from Figure 9 that the beam direction in $y z$-plane without conducting rod at the higher edge frequency is shifted from the desired direction $\left(\theta=0^{\circ}, 180^{\circ}\right.$ and $\left.\phi=90^{\circ}\right)$. Therefore, the conducting rod of the length $l_{p}$ is inserted at the upper wall of the ring to solve the tilted-beam problem. It is found that $l_{p}$ of $0.21 b(6 \mathrm{~mm})$ is appropriately chosen to obtain the widest bandwidth with minimized beam tilt in $y z$-plane at $10.6 \mathrm{GHz}$.

Although the conducting rod can mitigate the beam tilt problem at the higher edge frequency, the radiation pattern can be further improved. From the simulated results, it is found that the radiation pattern is still slightly tilted. Thus, the double ridges at the upper wall of the ring with the height $h_{u}$ and the position $s_{u}$ from the center are added to improve the radiation patterns at the higher edge frequency. To study the influence of the double ridges, the height $h_{u}$ is varied. From the results of parametric study, it is found that 


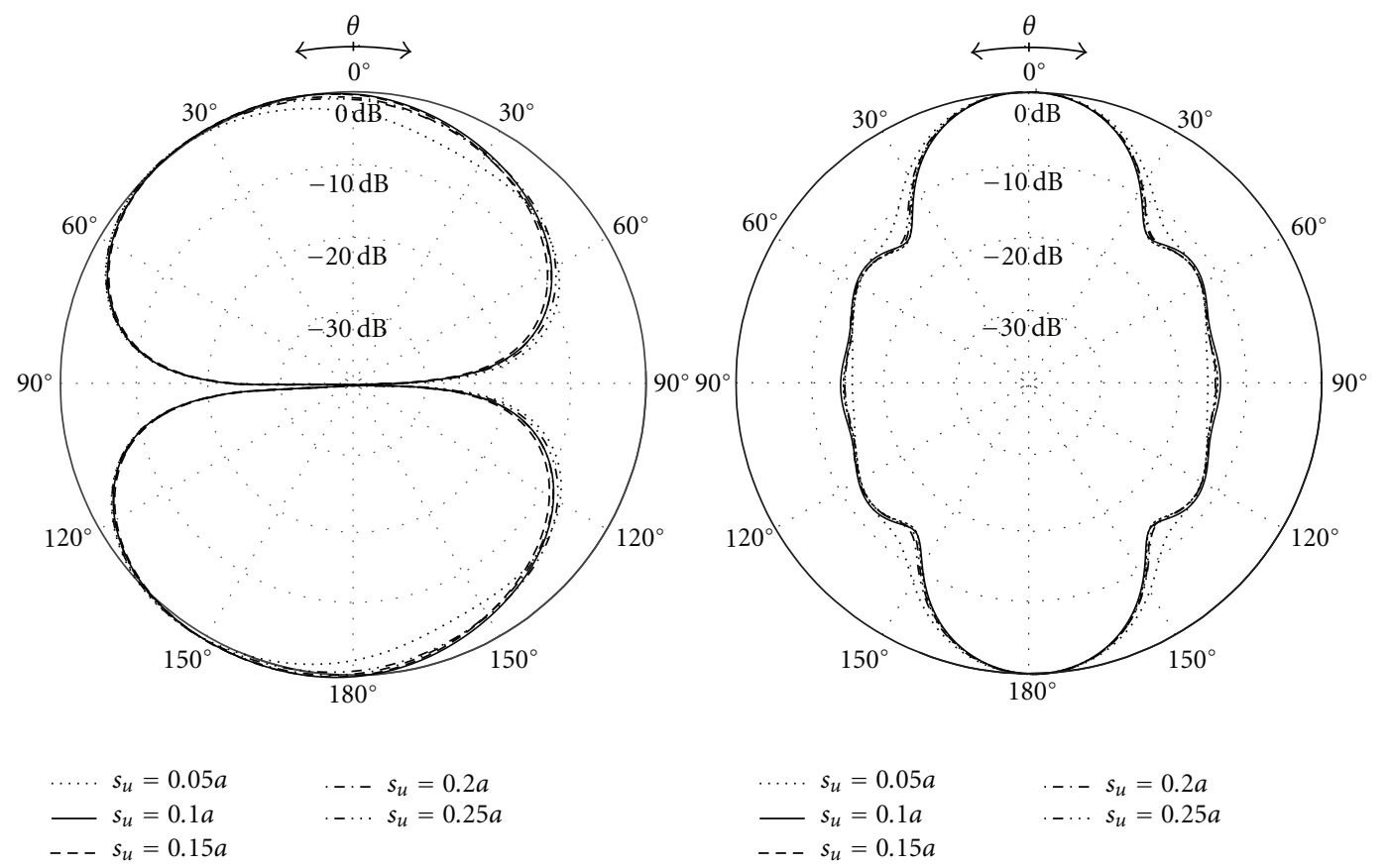

FIGURE 13: The radiation pattern in $y z$ and $x z$ planes as a function of $s_{u}$ at $10.6 \mathrm{GHz}$.

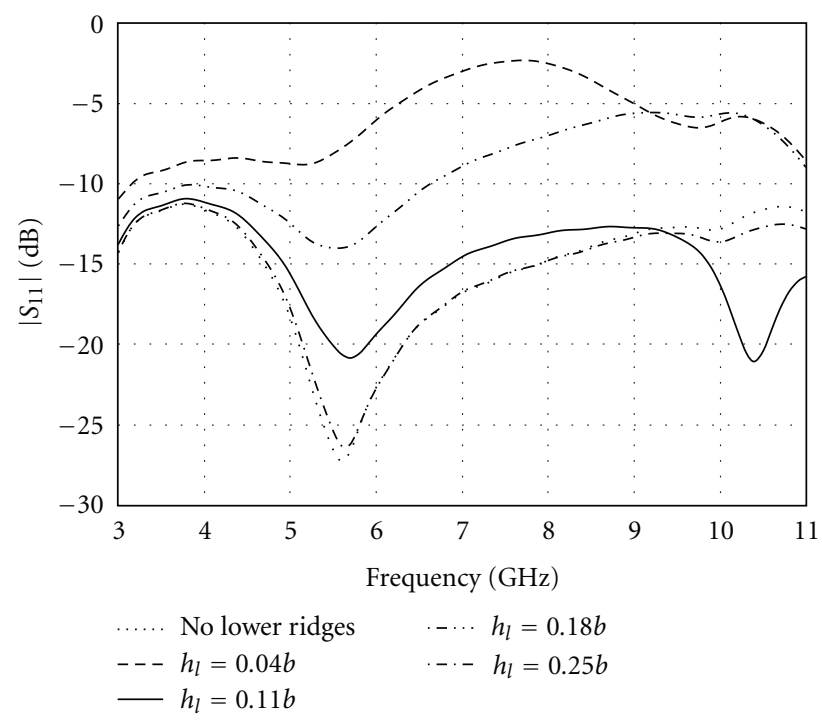

FIGURE 14: $\left|S_{11}\right|$ versus frequency as a function of $h_{l}$.

the height of double ridges equal or higher than $0.18 b$ can improve level of $\left|S_{11}\right|$ but the frequency band cannot cover UWB as shown in Figure 10. Instead, the double ridges of the length $0.11 b(3 \mathrm{~mm})$ can cover the UWB. From Figure 11, it is observed that the radiation pattern is slightly tilted when the frequency become higher. Moreover, to change the main beam to the desired direction, the positions $s_{u}$ are varied from $0.05 a$ to $0.25 a$. From the results, it is obvious that variation of $s_{u}$ does not affect to $\left|S_{11}\right|$ at the lower edge frequency as shown in Figure 12. When the frequency becomes higher than $9 \mathrm{GHz}$, the beam possesses minimum beam tilt when $s_{u}$ equals to $0.1 a(0.4 \mathrm{~cm})$ as shown in
Figure 13. As a result, $s_{u}$ of $0.1 a$ is selected as the design parameter.

To further determine the suitable parameter for the widest bandwidth and compact size, the height of double ridges $h_{l}$ and the position of ridge $s_{l}$ at the lower wall of the ring are varied. The height $h_{l}$ and the position of the ridge $s_{l}$ are varied at $0-0.25 b$ and $0.175 a-0.375 a$, respectively. From Figures 14 and 15, the impedance bandwidth and radiation pattern are depended on the height $h_{l}$ at the lower wall of the ring. From the results, it is found that $\left|S_{11}\right|$ is higher than $-10 \mathrm{~dB}$ making the bandwidth cannot cover UWB when the height of double ridges $h_{l}$ is increased higher than $0.11 b$. The 

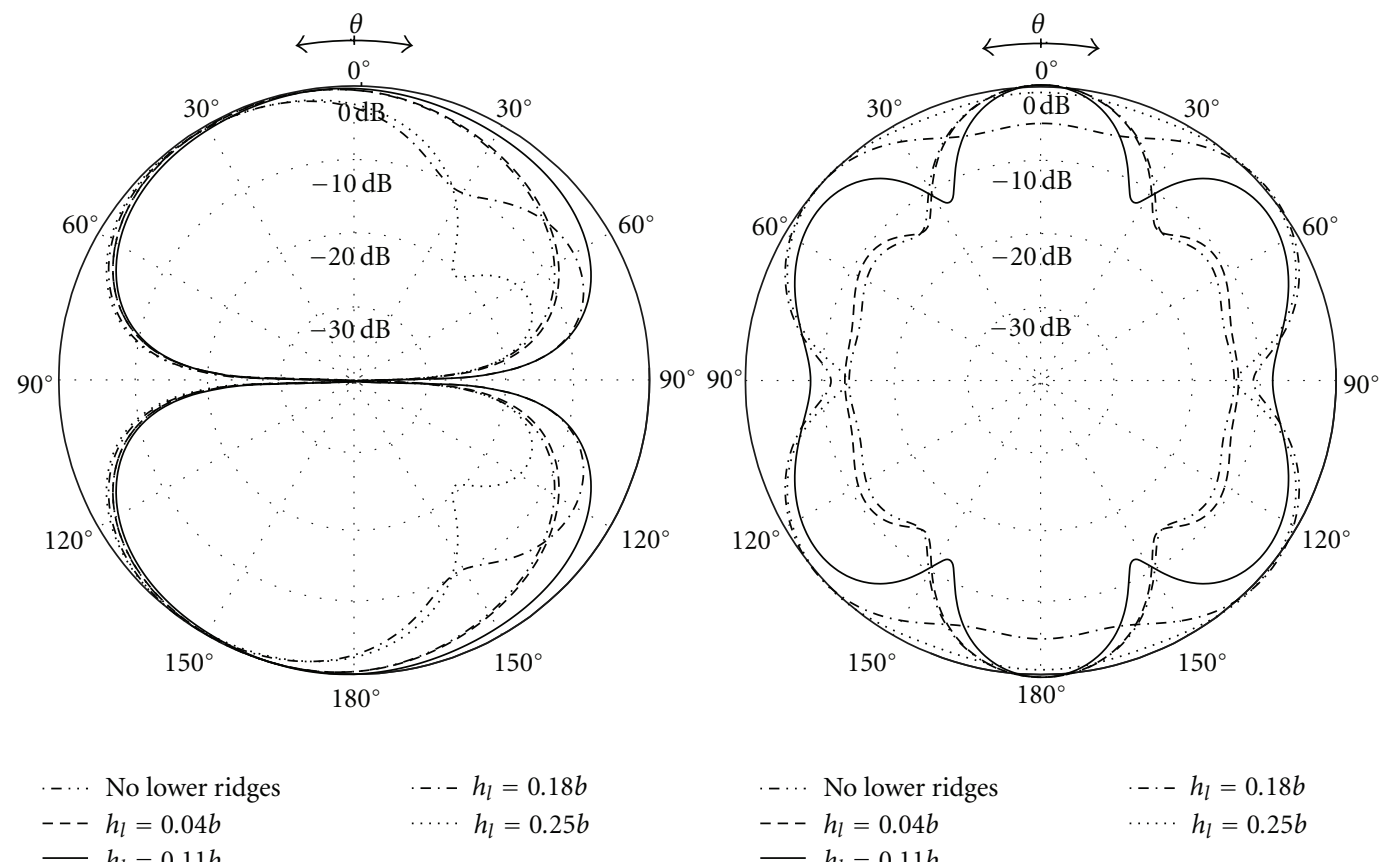

$$
\begin{aligned}
\cdots h_{l} & =0.18 b \\
\cdots \cdot h_{l} & =0.25 b
\end{aligned}
$$

$---h_{l}=0.04 b$

$h_{l}=0.25 b$

FIGURE 15: The radiation pattern in $y z$ and $x z$ planes as a function of $h_{l}$ at $10.6 \mathrm{GHz}$.

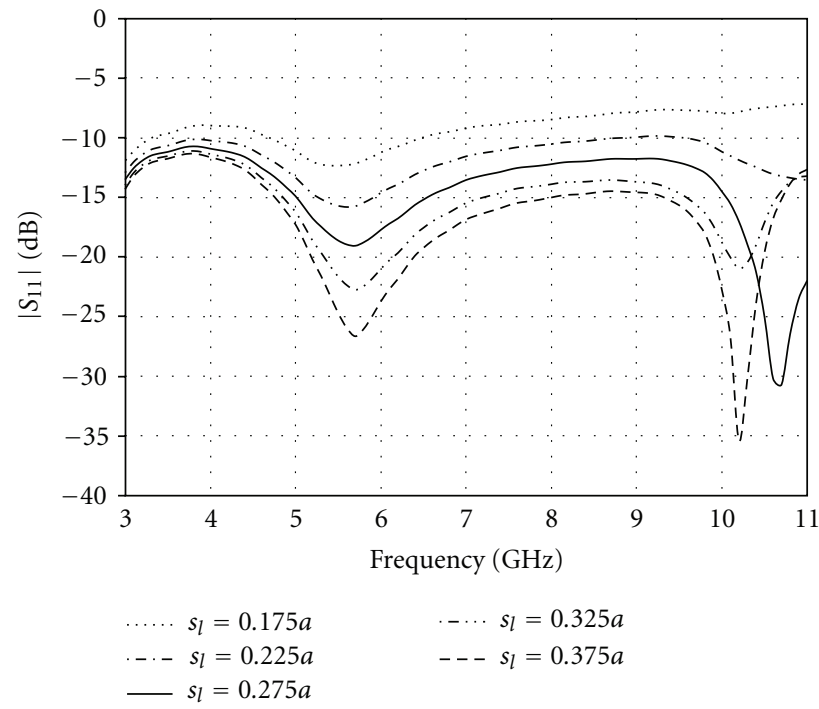

FIGURE 16: $\left|S_{11}\right|$ versus frequency as a function of $s_{l}$.

radiation patterns at the higher edge frequency will be worse with the increased height of double ridges at the lower wall of ring as illustrated in Figure 15. Moreover, the $\left|S_{11}\right|$ and radiation pattern at the higher edge frequency can be improved by varying the position of ridge $s_{l}$ at the lower wall of the ring. From the results, it is obvious that $\left|S_{11}\right|$ can be reduced to lower than $-10 \mathrm{~dB}$ with minimized beam tilt in $y z$-plane at 10.6 GHz when the position of ridge is increased as illustrated in Figures 16 and 17, respectively. Hence, the height of double ridges $h_{l}$ of $0.11 b(3 \mathrm{~mm})$ and the position of ridges $s_{l}$ of $0.275 a(1.1 \mathrm{~cm})$ are chosen as the design parameter.
Figures 18 and 19 show the compared $\left|S_{11}\right|$ of the proposed antenna by using CDM excited rectangular ring with rod and double ridges and without rod and double ridges. It is found that $\left|S_{11}\right|$ of the rectangular ring antenna fed by CDM without rod and double ridges is higher than $-10 \mathrm{~dB}$ at the higher edge frequency that makes this structure cannot cover the frequency band from 3.1 to 10.6 GHz. The bandwidth can be extended to cover the UWB frequency range by adding the rod and double ridges. Moreover, the radiation pattern at the higher edge frequency can also be improved with the rod and double ridges. 

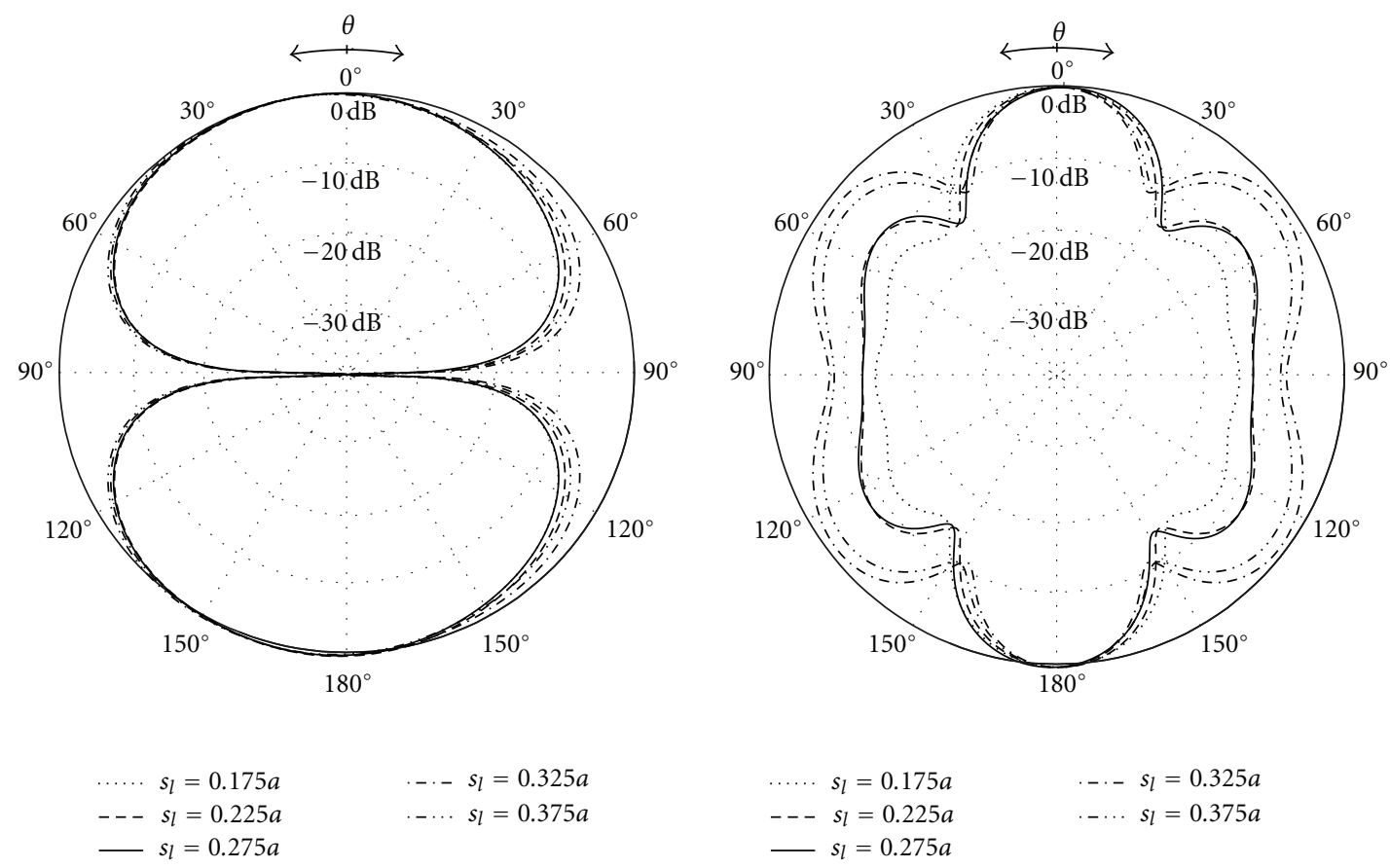

$-s_{l}=0.275 a$

FIGURE 17: The radiation pattern in $y z$ and $x z$ planes as a function of $s_{l}$ at $10.6 \mathrm{GHz}$.

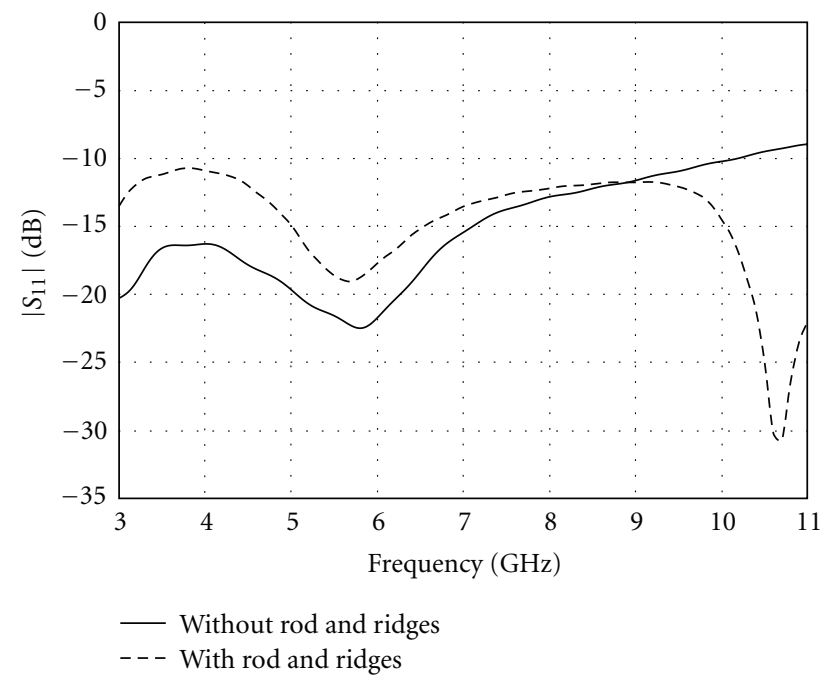

FIGURE 18: Comparison of $\left|S_{11}\right|$ between with and without rod and double ridges.

Ultimately, from the simulated results of the proposed antenna, the suitable parameters are obtained as tabulated in Table 1.

\section{Measured Results}

To confirm the simulated results, the prototype antenna with suitable parameters as tabulated in Table 1 was fabricated as depicted in Figure 20.
4.1. Impedance Bandwidth. The impedance characteristics and radiation pattern are measured by using an HP8720C Network Analyzer inside anechoic chamber. The compared $\left|S_{11}\right|$ between the simulated and measured impedance bandwidth is plotted in Figure 21. Apparently, the simulated and measured impedance bandwidths of $\left|\mathrm{S}_{11}\right|<-10 \mathrm{~dB}$ can cover the frequency range of 3-11 GHz. In addition, Figure 22 shows the simulated and measured gain at the desired direction $\left(\theta=0^{\circ}\right.$ and $\left.\phi=90^{\circ}\right)$ along the frequency 


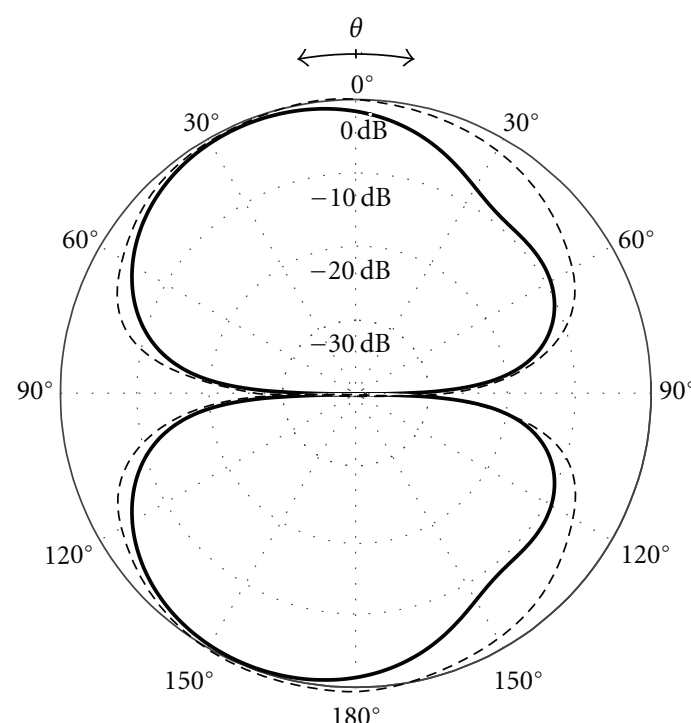

$180^{\circ}$

- Without rod and ridges - - - With rod and ridges

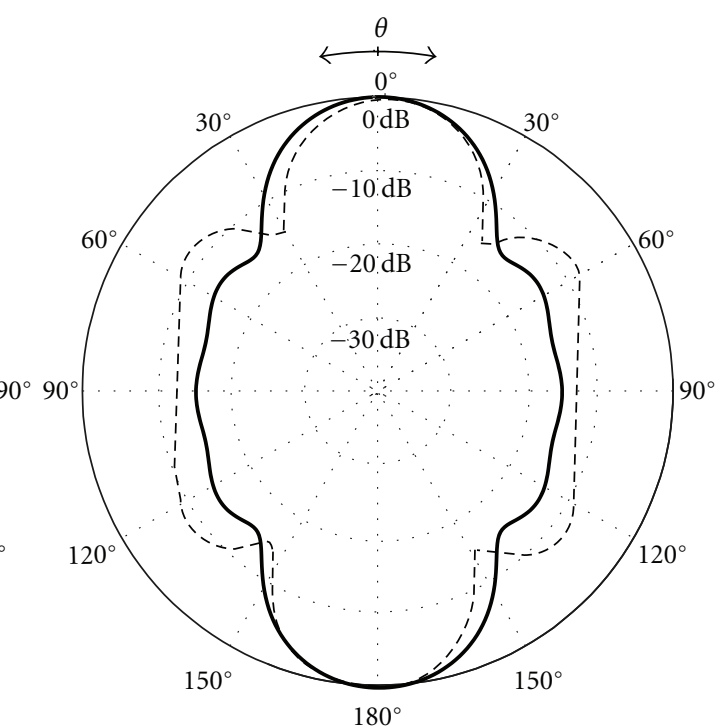

- Without rod and ridges - - - With rod and ridges

FIGURE 19: Comparison of radiation pattern with and without rod and double ridges in $y z$ and $x z$ planes at $10.60 \mathrm{GHz}$.

TABLE 1: Suitable antenna parameters.

\begin{tabular}{lcc}
\hline Parameter & Physical size & Electrical size $(\lambda)$ \\
\hline$a$ & $4.0 \mathrm{~cm}$ & 0.400 \\
$b$ & $2.8 \mathrm{~cm}$ & 0.280 \\
$c$ & $1.5 \mathrm{~cm}$ & 0.150 \\
$s_{l}$ & $1.1 \mathrm{~cm}$ & 0.110 \\
$s_{u}$ & $4.0 \mathrm{~mm}$ & 0.040 \\
$r_{c}$ & $7.7 \mathrm{~mm}$ & 0.077 \\
$l_{p}$ & $6.0 \mathrm{~mm}$ & 0.060 \\
$h_{u}$ & $3.0 \mathrm{~mm}$ & 0.030 \\
$h_{l}$ & $3.0 \mathrm{~mm}$ & 0.030 \\
\hline
\end{tabular}

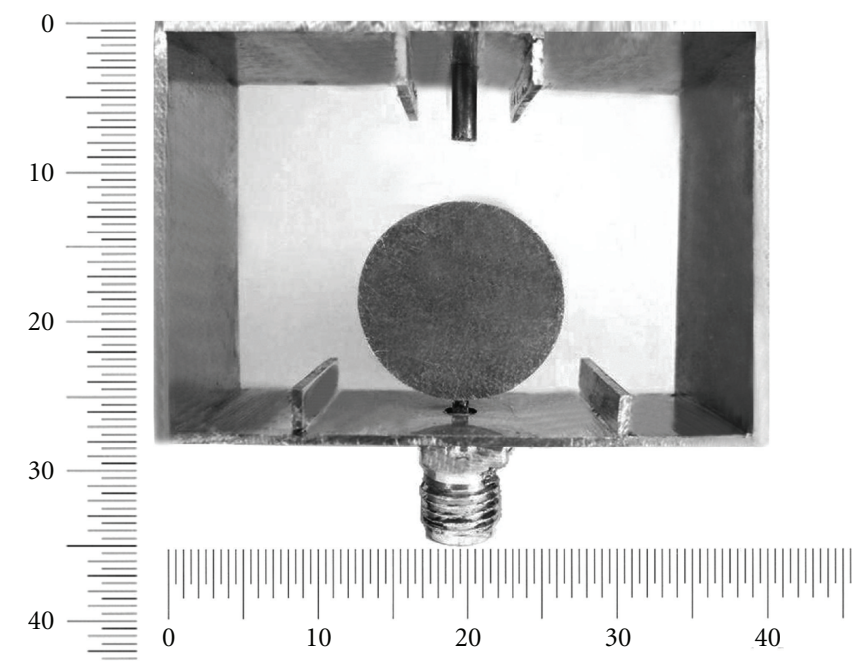

FIGURE 20: Photograph of the prototype antenna. 


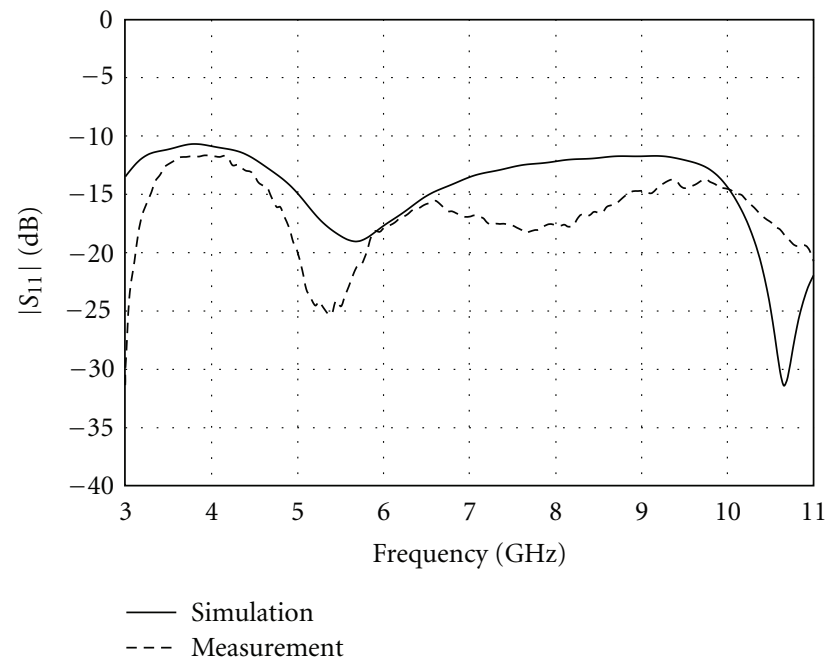

FIgURE 21: Compared $\left|S_{11}\right|$ between simulation and measurement.

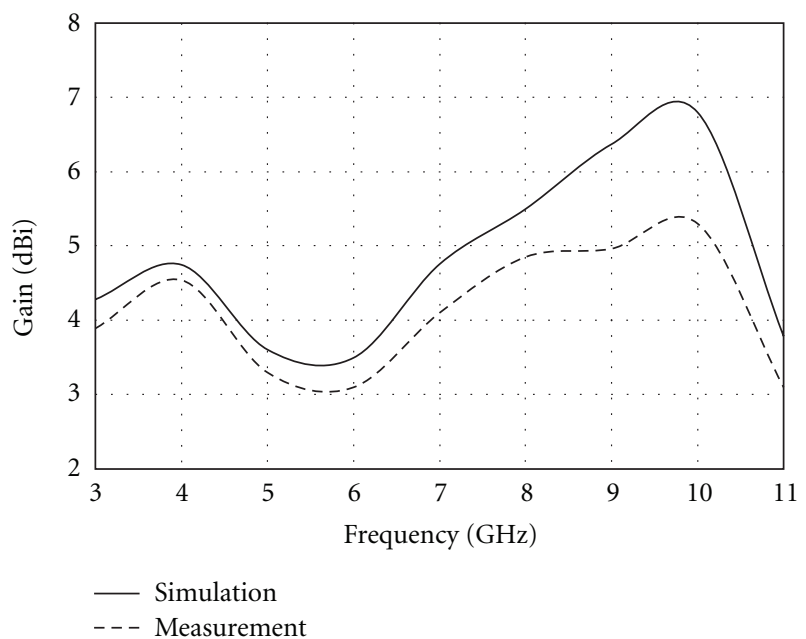

FIGURE 22: Simulated and measured gain.

range of 3.1-10.6 GHz. The minimum and maximum gains from the simulation and measurement are 3.5-6.9 dBi and 3.1-5.3 dBi, respectively.

4.2. Radiation Pattern. The simulated and measured radiation patterns in the $y z$ - and $x z$-planes at 3.1, 6.8, and 10.6 GHz are shown in Figure 23. It is obvious that the beam peak directs to the $+z$ and $-z$ directions. Furthermore, it is found that the radiation pattern in the $y z$-plane is slightly tilted from $z$ axis at the higher frequency because of the present CDM located at the lower wall of rectangular ring making unsymmetrical structure the upper and lower parts of the ring. Due to the symmetrical structure along left and right part of the ring, the radiation pattern is symmetry in $x z$-plane. The radiation patterns from simulation and measurement in the $y z$ - and $x z$-planes are in good agreement.

\section{Conclusions}

The rectangular ring antenna fed by CDM with conducting rod and double ridges is proposed for an antenna at the base station of ultra-wideband applications. This antenna radiates bidirectional pattern with constant beam direction over the UWB frequency. The effect of antenna parameters to $\left|S_{11}\right|$ characteristics and the radiation patterns is investigated by parametric study. This antenna possesses the maximum gain from the measurement of $5.3 \mathrm{dBi}$ at $9.8 \mathrm{GHz}$ and higher than $3 \mathrm{dBi}$ for the frequency range from 3.1 to 10.6 GHz. The impedance bandwidth of $\left|\mathrm{S}_{11}\right|<-10 \mathrm{~dB}$ can cover the frequency range of UWB. Since the proposed antenna possesses the compact size and good radiation performance, it can be a potential candidate for ultrawideband applications. 

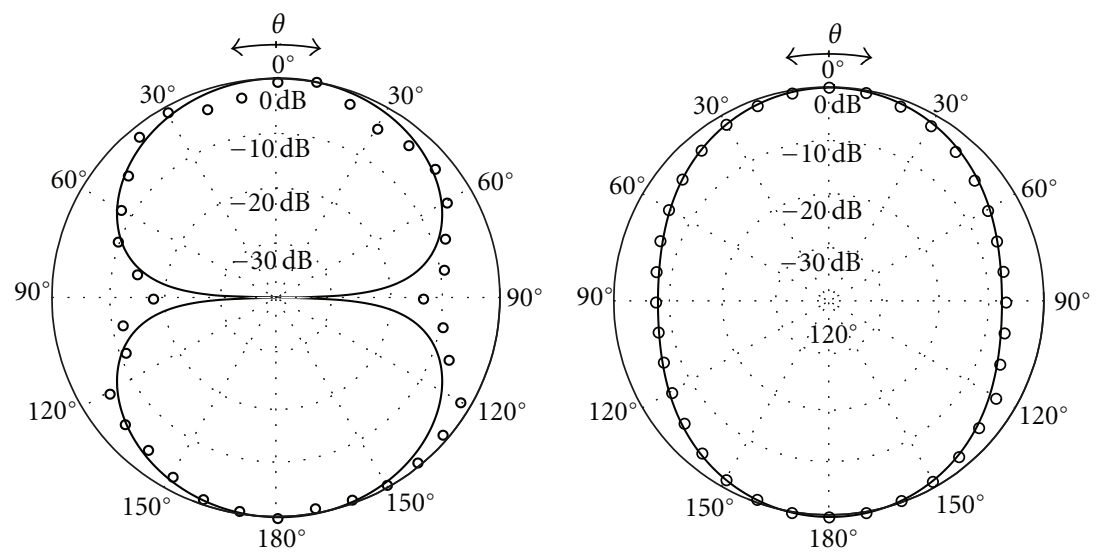

(a)
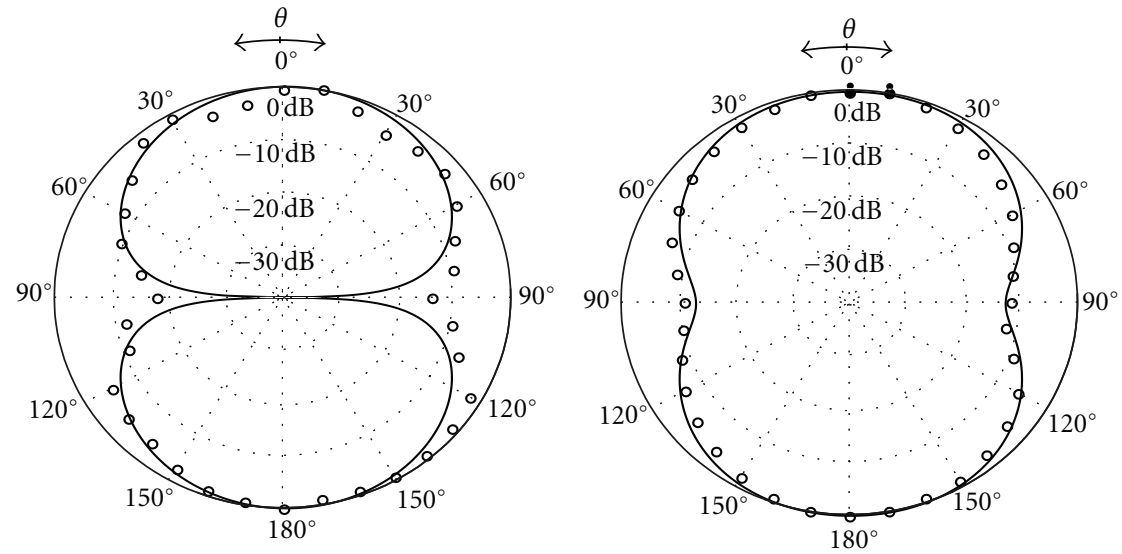

(b)
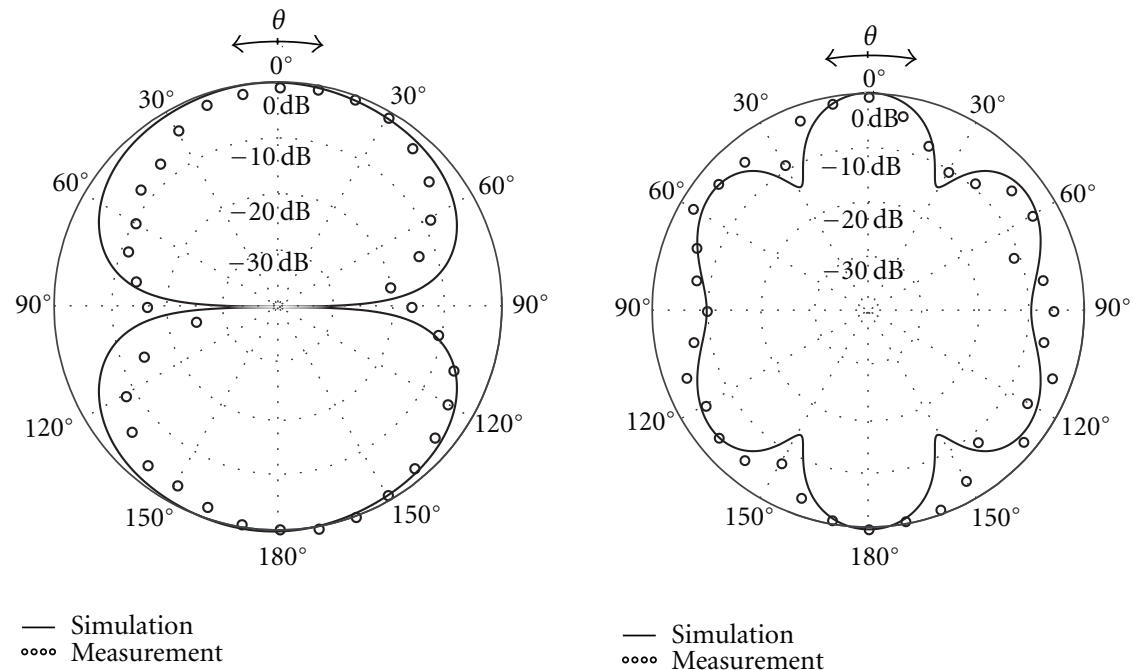

- Simulation
.oo० Measurement

ooo॰ Measurement

(c)

FIGURE 23: The comparison between the simulated and measured radiation pattern in $y z$ and $x z$ planes. 


\section{Acknowledgment}

This work is supported by AUN/Seed-Net Program.

\section{References}

[1] Federal Communications Commission, "First order and report: revision of part 15 of the commission's rules regarding UWB transmission systems," April 2002.

[2] M. Hammoud, P. Poey, and F. Colombel, "Matching the input impedance of a broadband disc monopole," Electronics Letters, vol. 29, no. 4, pp. 406-407, 1993.

[3] C. Phongcharoenpanich, S. Lamultree, S. Kosulvit, and M. Krairiksh, "Theory and experiment of an antenna using a probe excited rectangular ring," in Proceedings of the IEEE International Symposium on Antennas and Propagation and USNC/CNC/URSI North American Radio Science Meeting, vol. 3, pp. 737-740, June 2003.

[4] K. Chawanonphithak, C. Phongcharoenpanich, S. Kosulvit, and M. Krairiksh, "Characteristics of an elliptical ring antenna excited by a linear electric probe," International Journal of Electronics, vol. 94, no. 10, pp. 973-984, 2007.

[5] S. Kosulvit, C. Phongcharoenpanich, M. Krairiksh, and T. Wakabayashi, "Radiation characteristics of a bidirectional antenna using a probe excited circular ring," in Proceedings of the IEEE International Symposium. On Intelligent Signal Processing and Communication Systems, pp. 713-716, December 1999.

[6] S. Lamultree and C. Phongcharoenpanich, "Full-wave investigations of a probe-excited rectangular ring antenna by method of moments with RWG basis functions," PIERC, vol. 8, pp. 161-177, 2009.

[7] L. Wei, Q. Jinghui, and S. Ying, "Design and simulation of novel ultra wideband planar reflector antenna," in Proceedings of the International Conference on Microwave and Millimeter Wave Technology (ICMMT '07), pp. 1-4, April 2007.

[8] C. Phongcharoenpanich, S. Lamultree, S. Kosulvit, M. Krairiksh, and J. Takada, "Analysis of a dihedral corner reflector antenna excited by a probe inside rectangular ring," in Proceedings of the International Symposium on Antennas and Propagation, pp. 225-228, August 2004.

[9] J. D. Kraus, “The corner-reflector antenna," Proceedings of the IRE, vol. 28, pp. 513-519, 1940.

[10] P. T. Lam, S. W. Lee, K. C. Lang, and D. C. D. Chang, "Sidelobe reduction of a parabolic reflector with auxiliary reflectors," IEEE Transactions on Antennas and Propagation, vol. AP-35, no. 12, pp. 1367-1374, 1987.

[11] G. Ketwan, C. Phongcharoenpanich, and S. Kosulvit, "A wideband unidirectional antenna using conical reflector fed by circular ring," in Proceedings of the Asia-Pacific Microwave Conference, pp. 2939-2942, December 2005.

[12] N. P. Agrawall, G. Kumar, and K. P. Ray, "Wide-band planar monopole antennas," IEEE Transactions on Antennas and Propagation, vol. 46, no. 2, pp. 294-295, 1998.

[13] Z. N. Chen, M. J. Ammann, M. Y. W. Chia, and T. S. P. See, "Annular planar monopole antennas," IEE Proceedings: Microwaves, Antennas and Propagation, vol. 149, no. 4, pp. 200-203, 2002.

[14] M. J. Ammann and Z. N. Chen, "Wideband monopole antennas for multi-band wireless systems," IEEE Antennas and Propagation Magazine, vol. 45, no. 2, pp. 146-150, 2003.
[15] J. Liang, L. Guo, C. C. Chiau, X. Chen, and C. G. Parini, "Study of CPW-fed circular disc monopole antenna for ultra wideband applications," IEE Proceedings Microwaves, Antennas and Propagation, vol. 152, no. 6, pp. 505-508, 2005.

[16] CST-Microwave Studio, User’s Manual, 2006. 

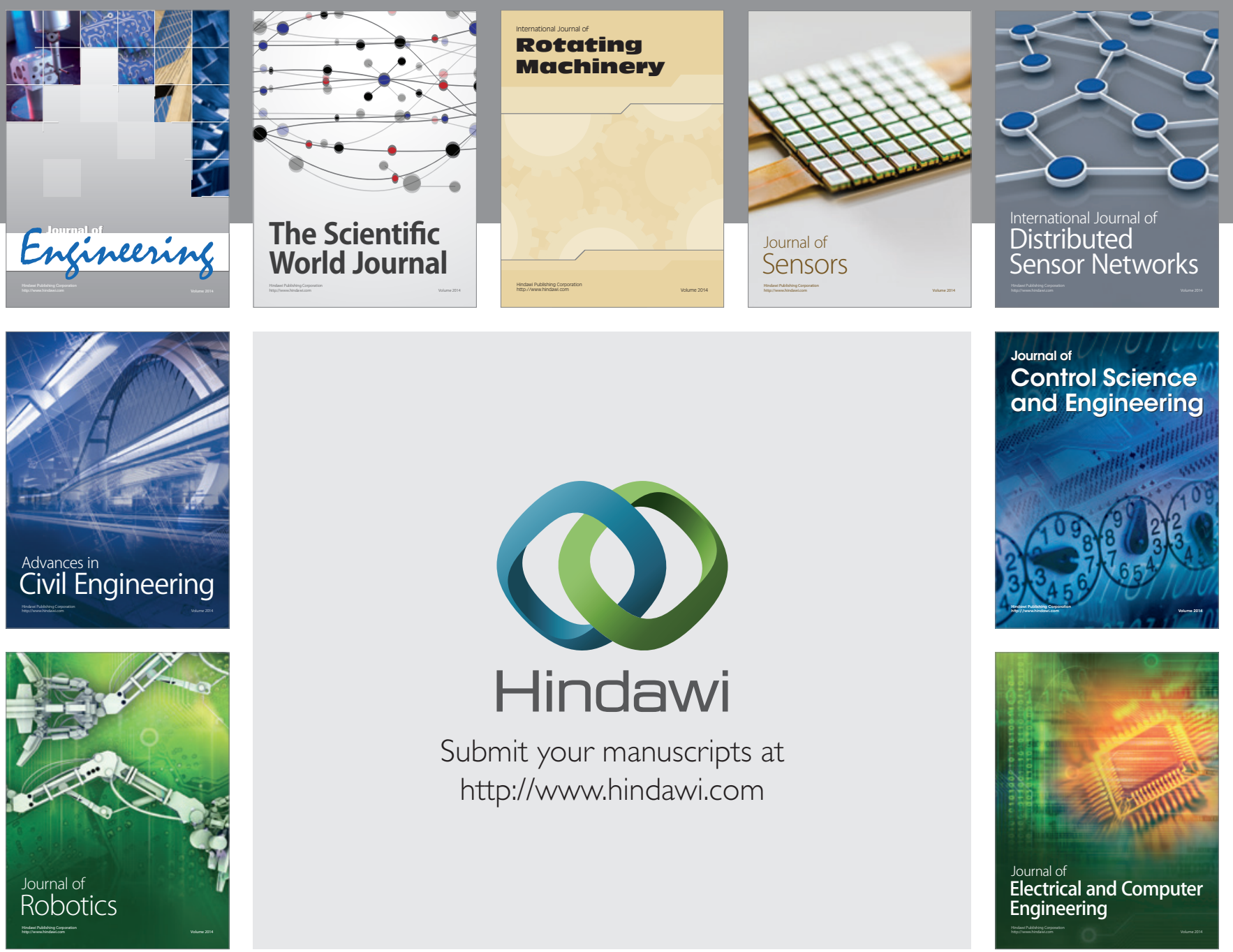

Submit your manuscripts at

http://www.hindawi.com
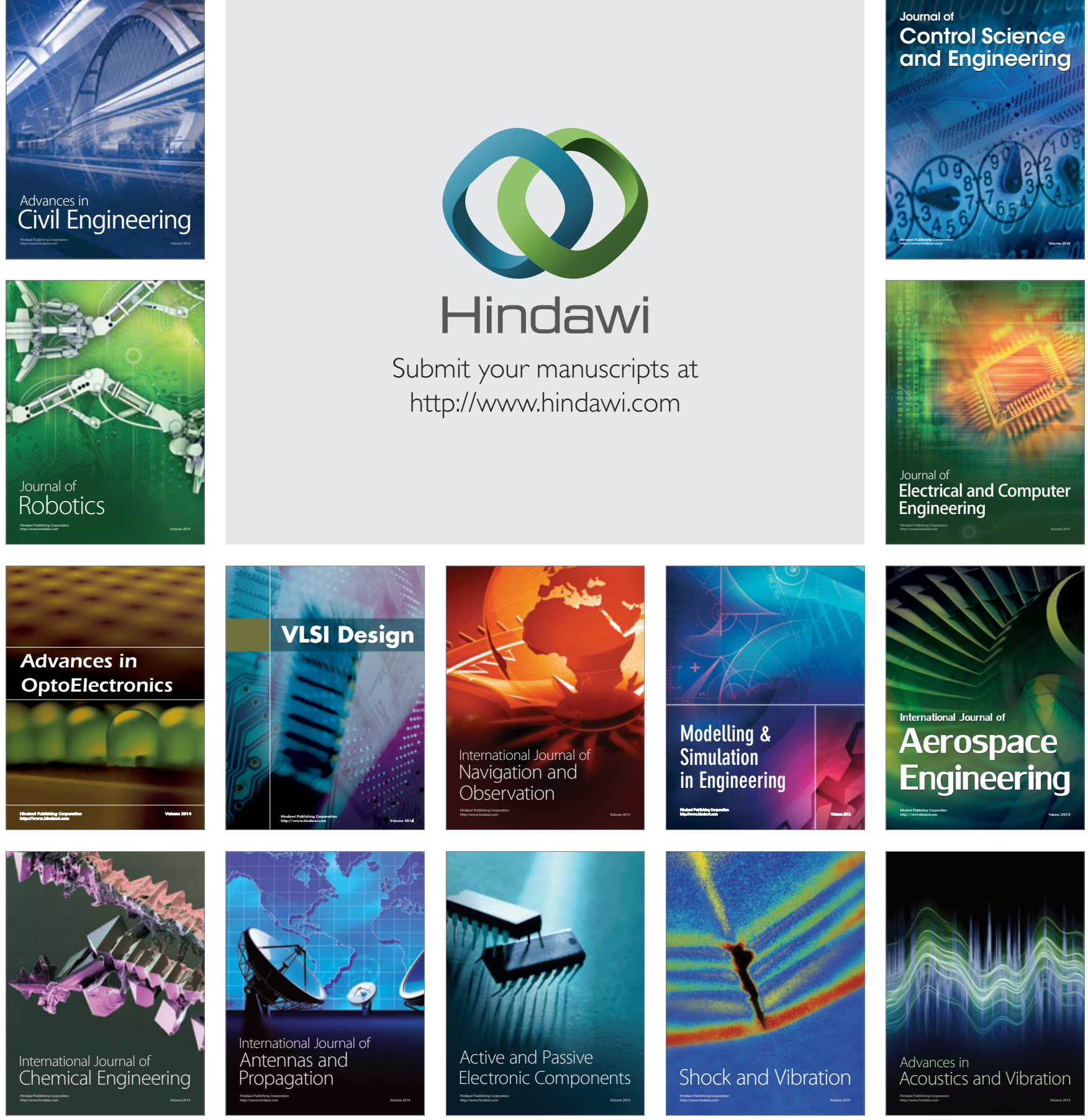